\title{
Challenges and countermeasures faced by financial personnel under financial robots
}

\author{
Liujing ${ }^{1,}$, liqin Zhang ${ }^{2, b}$ \\ ${ }^{1}$ Department of law, wuhan university of technology, wuhan, hubei, China \\ ${ }^{2}$ Department of law, wuhan university of technology, wuhan, hubei, China \\ a767831513@qq.com, b757460362@qq.com \\ *Liujing
}

Keywords: financial robot; financial personnel; future development; coping strategies

\begin{abstract}
The implementation of Deloitte's financial robot has made the prospect of financial robots optimistic. The financial robot as an accounting tool is the product of the development of intelligent era. The financial intelligence will bring a new round of accounting. Change, which led to the repositioning of accounting positions. In the past two years since the listing of Financial Robots, the paper analyzes the functional characteristics of financial robots and the impact of financial robots on accounting positions and traditional accounting personnel, and expounds the development direction and coping strategies of future financial personnel.
\end{abstract}

\section{财务机器人下财务人员面临的挑战和对策 \\ 刘静 $1, a$, 张丽琴 $2, b,{ }^{*}$ \\ 1 武汉理工大学法学系, 武汉, 湖北, 中国 \\ 2 武汉理工大学法学系, 武汉, 湖北, 中国 \\ a767831513@qq.com,b757460362@qq.com \\ *刘静}

关键词：财务机器人；财务人员；未来发展；应对策略

摘要. 德勤“财务机器人”的推行上市, 使得目前对于财务机器人的前景市场一片看好, 作为会 计核算工具的财务机器人, 是智能化时代发展下的产物, 财务智能化会带来新一轮的会计变 革, 从而导致会计岗位被重新定位, 通过分析财务机器人的功能特点及财务机器人对会计岗位 和传统会计人员的影响，阐述未来财务人员的发展方向和应对策略。

1. 引言

随着科学技术的不断发展，人工智能已经在人们的生活中得到了广泛应用，财务智能工 具在智能时代下应运而生。从 2017 年 5 月份以来，德勤率先推出“财务机器人”，普华永道、 安永和毕马威也相继推出了财务机器人, 财务机器人的推广上市在财会界及其他领域引起了 较大轰动，也使得财务人员及其相关领域人员工作面临着巨大的挑战。 


\section{2.财务机器人}

\section{1 财务机器人出现的意义}

财务机器人是人工智能在财务领域的应用之一, 是将机器人流程自动化（RPA， Robotic Process Automation）在财务领域的应用简称为财务机器人， RPA 是通过执行重复的基于规则 的任务, 来将手工活动进行自动化的一种技术, 而财务机器人就是 RPA 在财务领域的应用。 简单说来, 就是在电脑上装一个机器人软件, 对这个软件根据需要设置财务操作规则, 进行 简单的自动化操作, 它以虚拟员工形式参与企业的财务活动, 从而降低人力成本的投入。

\section{2 财务机器人的作用}

“财务机器人”不仅可以处理一些简单的基础性任务, 完成高度重复的业务工作，降低人 力资源的投入并减少对应工作时间，在处理相关数据的时候具有非常高的准确性，并且它有 着非常强大的存储空间, 能够全面检查和记录相关数据, 使得数据具有完整性和连贯性, 以 满足不同时期的备查需求，确保数据真实可靠; 还能够进行对账工作，每天可自动完成 15 家 银行的 80 个银行账号的对账以及调表打印工作, 并且在操作过程中不需要任何人为干预, 可 见其强大的自动化处理功能; 1(P135)“财务机器人”不仅可以对增值税发票验证真伪, 还能够将 需要查验的增值税发票验证后, 将数据提交到国家税务总局官方查验平台进行备案核对, 然 后将验证结果反馈给相关人员并且记录下数据结果。

\section{3 财务机器人的功能及使用情况}

1.“四大”财务机器人主要功能对比。“四大”将财务机器人推广投入财务领域中, 普华永道、 德勤宣称其财务机器人的主要功能是完成核算类、收集类等重复性高的、技能要求低的基础 性工作; 安永宣称其财务机器人具有 RPA 认知、智能学习、数据分析等功能; 毕马威推出的 财务机器人则有帮助员工制定多方面的战略和路线图, 选择合适的合作商等功能。（如表一） 2(P4-5)

2.财务机器人使用情况。2 017 年 5 月, 德勤财务机器人推出后不久, 便受到数十家大型 企业的青睐和支持; 随后, 普华永道推出了自己研发出的财务机器人业务解决方案, 并在中 化国际等大型著名企业投入运营; 安永推出了 “安哥”智能财务机器人，并声称其适合企业各 项业务流程; 毕马威利用微软 Azure 智能云技术结合人工智能技术推出的自动化解决方案在 银行试点运用成功。除了“四大”推出的财务机器人亮相市场外, 我国许多企业也纷纷看中智 能化的巨大市场潜力, 开始投入财务机器人领域的开发研究。例如长沙智能制造总院研发推 出的“会计机器人”已经为五十多家不同类型的企业提供服务，金蝶研发推出的智能财务机器 人受到当下企业的追捧。越来越多的企业通过引入智能财务机器人的方式, 开始迈入财务工 作系统向智能化领域转型的步伐, 以适应未来企业的发展趋势。

\section{3.财务机器人给财务工作带来的机遇和挑战}

\section{1 传统财务工作的弊端}

传统财务工作主要是对经济活动的事后记录，从对经济活动的核算，到审核录入会计凭 证, 再在账簿上进行登记, 最后过渡到财务报表对外批露的核算过程。这个过程涉及很多的 基础性核算工作，人工处理需要耗费大量人力成本和时间成本，这些核算过程中存在很多缺 陷, 主要包括: 第一, 报账核算方面。一个企业一般需要 2 至 3 位会计人员专职处理报账审 核业务、核算业务, 进行原始发票的审核和汇总, 工作较单一且重复性高。第二, 凭证录入 工作。传统会计人员的工作大多在凭证录入上, 只需要根据业务类型在记账软件上选好会计 分录, 录入数字汇总, 存在大量简单重复性高的工作。第三，编制报表。一个企业的财务部 门会面对大量的报表，不仅包含日报、周报、月报和季报，还要根据不同部门主管要求分开 
填列, 通常一个报表的数据填完后还需要把这个数据填在另外一张报表上面，会计人员会花 费大量的时间和精力进行这类数据的收集和汇总。第四，其他基础核算类工作。一个企业的 财务不仅仅只包括凭证审核、编制凭证和填制报表，还包含很多其他工作，例如开税票、装 凭证、数据统计等日常工作，周而复始基础性工作的准确性难以保证。

\section{2 财务机器人带来的机遇}

1.提高财务工作效率。在传统会计时代，大多数会计人员手工审查和填制会计凭证、登 记会计账簿、编制财务报表, 不断重复进行基础性的财务会计核算, 其工作量不仅大且运算 和记录效率也较低。在上线财务机器人后, 它可取代财务作业流程中的手工操作, 监督和控 制各自动化财务流程、录入会计信息、合并会计数据等, 因此财务工作中这些大量基础性业 务都可由财务机器人完成, 把会计人员从不断重复的劳动中解放出来。只需要财务人员把增 值税发票放入扫描仪中进行扫描验证, 剩下的工作可全部都由机器人完成, 完全可以顶替多 个财务人员的日常基础性工作，大大提高了财务的日常工作效率。

2.减少会计信息不实。公司经营的财务数据的真实性、可靠性对一家公司的信息披露至 关重要, 是企业管理层、投资者做出正确投资经营判断的决定性因素之一。数据的汇总、填 制、报送人为操作的错误率因素有很多方面, 和会计人员的环境影响、工作能力、细心程度、 熟练程度及心理因素有关; 其次, 出于特殊盈利目的考量, 会计人员会对某些亏损金额数据 进行调整, 出现舞弊做假账的情况。但是财务机器人可利用其强大的数据收集、记忆功能, 其完成任务的每个步骤都可被系统监控和记录, 留有工作痕迹, 从而可作为审查证据以满足 审计合规性审查, 真实性更加可靠, 可避免出现虚假的会计信息。

3. 业务稳定性能好。会计人员在日常工作当中，容易受到外部因素和内部因素的影响， 对工作环境、薪酬标准、晋升空间及工作氛围有一定要求和标准, 在内外部环境没有达到预 期目标值时, 或者内外部环境发生改变而自己难以适应或接受时, 会造成人员流动, 对企业 岗位的日常工作业务的正常运转造成一定影响。但是财务机器人在日常工作中, 基本不会因 为内外部环境而影响日常工作, 在工作之余不会抱怨, 产生消极情绪, 破坏企业员工的团结 凝聚力, 一定程度上保障了工作的稳定性。

4.工作时长优势大。面对财务人员的 $5 \times 8$ 的法定工作时长，以及婚假、产假、及法定节 假日, 可利用的规定工作时间并不多, 且遇到特殊的业务忙碌期需要加班时, 还需要支付加 班费、交通费甚至补贴等费用, 会增加企业一定的加班成本, 而财务机器人每周可工作时长 是 $7 \times 24$ 小时的可连续工作时间, 并且没有一些个人因素的请假、加班等费用成本, 因此在工 作时长方面, 财务机器人的优势较大, 作为虚拟劳动力进入企业, 广受企业家欢迎。

5.适应多样化岗位时效短。财务机器人可进行一些录入凭证、数据汇总、纳税申报等基 础性工作，根据这些工作内容，可代替多个不同财务岗位，一个财务岗位正常上岗周期是二 至三周, 且是在业务不太庞杂的企业, 如果一个会计人员需要同时适应以上机器人能取代的 工作岗位, 那么少则八周多则十二周, 而财务机器人的快速上线操作优势, 只需要二至六周 即可，极大的提高了岗位的上线效率。

\section{3 财务机器人弊端}

“财务机器人”虽然带来了许多的便利, 但它仍处于智能开发的初级阶段, 还不具备机器 自主学习功能, 自动化流程还是基于特定单一流程的程式开发, 仅仅是人工智能技术和会计 的业务流程初步结合。根据目前“财务机器人”具备的功能以及使用情况来看, 其主要作用是 帮助财务部门进行基础核算工作, 它的优势只适合一些高重复性、业务标准化程度高和业务 规则明确的企业进行, 因此, 在需要根据复杂情况进行人工判断、人工分析的财务管理范畴, 而且对于大多数制度流程不太完善甚至不太健全且业务量不多的小企业而言, 这些企业的财 务人员大多在本职财务工作以外又要协助处理人事管理、客户沟通等工作, 因此财务机器人 
的作用对于小企业就没那么大，它的使用范围对于小企业而言就极其有限了。

人工智能减少了人对数据信息的参与操作度, 财务机器人在网络环境中就难免被恶意操 控和利用, 所以在机器人自动化处理模式下, 如果网络信息安全工作不到位, 给企业和国家 带来的不良后果也是灾难性的，财务机器人的出现也带来了新的不可估量的风险。

当前财务机器人的发展速度已经超过了国内相关法律的更新范畴, 这就难免会在提供智 能便利的同时，也相继带来相应的法律风险。从法律角度上看，如果财务机器人以“员工”的 身份出现, 那么它通过流程设定得出的数据结果产生的法律纠纷, 这个经济后果和法律责任 该由谁来承担, 这个法律问题还待解决。

\section{4.财务机器人下会计人员的应对策略}

\section{1 财务人员的应对措施}

1. 财务人员转型。财务共享中心、大数据的应用、互联网+等出现，使得传统财务会计的 以规范为核心的会计核算向成本管理、预算管理、绩效管理、投融资管理等管理会计领域转 变，财务通过与业务的深度融合，从价值的参与者向价值的创造者转变。国内企业超过 $85 \%$ 的财务人士担任基础核算会计职位，他们的大部分时间用于记录与核算，充当着“账房先生” 的角色, 因此不能再将眼光局限于账簿表面的数据, 而要借大数据多角度分析其背后的实际 经济意义。3(P91-92)实现从传统会计到管理会计的转型方向是大势所趋, 也是在财务机器人时 代不得不进行会计行业改革的大方向。

2.提升专业技能。财务机器人目前还只能处理一些固定基础化的信息处理工作，还不具 备学习思考的能力, 财务人员应该抓住机器人的这一弱势, 提升自己的专业技能, 接纳和利 用机器人, 利用机器人分析获得更准确的数据, 更好地进行决策、预测等, 使长期处于基础 岗位的会计人员不再局限于账簿表面的数据汇集工作，让他们参与企业的规划、决策、预测 中。因此要制定职业规划, 学习各方面知识和工作方法, 建立完善全面的知识体系, 拥有发 展的战略眼光, 使财务工作向着高端方向发展, 才能在未来财务市场上占据主导权。未来会 计人员要深入地了解公司业务, 拥有透过市场与公司数据看到更深层次问题与机会的能力, 战略型、管理型的会计是财务人员在新环境下的努力方向。4(P233)

3.转变思维模式。我们已经迎来了大数据时代, 财务机器人在智能时代的发展下应运而 生已是不可逆转的事实, 作为财务人员应该积极拥抱和接纳, 主动参与到各种新型技术的学 习和掌握之中, 用正确的观念来审视财务机器人给会计人员在财务工作中带来的便利, 让会 计人员在紧张忙碌的工作之余有更多时间和精力去思考和关注基础核算工作以外的事情, 而 不是一味的拒绝和恐慌财务机器人夺走了会计人员的“饭碗”, 要转变思维方式, 建立自动化 思路, 树立起机器人管理者的意识, 积极的做出改变以适应时代的变化。

\section{2 企业的应对方向}

1.完善财务管理模式。不管是国内还是国外，目前财务机器人在会计领域的使用还是比 较新颖的概念，一些规章制度、体系完善的大中型企业应主动拥抱财务智能化，推动传统财 务管理向智能财务管理的方向发展, 利用财务机器人先进的智能技术支持, 结合自身实际情 况和发展特点, 完善企业财务制度管理, 实现财务智能化和公司业务特点紧密融合, 进一步 提高财务管理工作的效率与质量，为企业创造更多的经济效益。

2.增加信息安全防范。随着技术网络的发展, 数据信息的泄露也是企业面临的一大问题, 企业在利用技术信息带来经济效益的同时, 其商业信息也在不知不觉中被网络公开化。财务 机器人的应用也是推进了财务信息数据网络化的发展, 这就要求企业在信息网络安全方面, 做好财务信息系统的信息安全防范工作, 在准备上线财务机器人之前, 多方位的收集财务机 器人的信息, 多次测试软件处理业务流程过程中的可靠性、保密性及稳定性, 在启动后实时 监控其运行的各个环节，以增强企业的财务信息安全性。 
3.提高财务机器人性能。目前市面上的财务机器人还仅限于一些基础化的核算工作，上 升不到高端的分析预测方面，且使用范围有限，价格十分昂贵，对于一些中小型企业则上线 财务机器人的性价比不高, 因此对于软件开发厂商而言, 应该针对不同企业需求和市场环境 特点, 设计出不同类型、不同功能、不同价格的财务机器人供企业选择, 同时也要在机器技 术上做出一定提高，多设定出高质量的机器人，满足市场不同的需求。

\section{3 国家层面的策略}

1.加强会计人员教育。现代经济的高速发展，使得企业对于会计岗位职能需求发生了极 大的变化, 传统会计职能与现代企业运营要求已经出现了较为明显的差异, 会计岗位在企业 中的职能范围正在不断拓展。各高校在开设会计专业的相关课程时, 要顺应时代潮流推陈出 新, 不应局限在过去单一式的专业知识技能培养, 应该根据学生就业方向进行分析和预判, 找准市场会计岗位上的需求对症下药, 将具体岗位要求和专业技能结合起来, 不仅要学习会 计基础理论核算知识, 建立完整的知识架构体系, 还要学习新型的技术管理知识, 如计算机 技术、财务管理、预测分析等，为企业和社会培养出更多符合市场需求的多技能型人才。

2. 完善相关法律法规。当前财务机器人还处于弱人工智能阶段, 未来经过不断地更新改 造之后，能够进入一定领域的分析、预测和管理，不仅具备财务人的专业知识，还具备了思 维学习能力, 发展到强智能阶段时, 那时的财务机器人就相当于独立的“企业员工”, 则现阶 段的法律原则和规范已不再适用, 通过财务机器人得出的会计结果而产生的经济纠纷, 应该 有一个明确的法律界定和规范, 以免破坏和扰乱市场经济秩序。相关机构应该紧密关注人工 智能对会计领域产生的影响, 既要完善会计标准体系及配套机制, 又要加快修订有关会计法 律法规制度。5(P5-6)以便立法者从法律的角度可以结合最新的会计相关制度，更有效、更精确 地对未来强智能化财务机器人的法律风险进行风险规避，达到事前控制的目的。

\section{5.结语}

财务机器人的出现是人工智能技术下的产物, 是科学技术进步的体现。它为会计行业的 发展和进步带来了巨大变革，提高了工作效率，推动了传统财务人员对职业发展的进一步规 划, 促进会计人员的职业架构转型, 充分利用财务机器人带来的便利, 完善自身知识体系, 规划自己的职业发展，为成为复合型人才做好充分的准备。

\section{References}

[1] Lin Chen. Analysis on the impact of "financial robot" on accounting practitioners [J]. Finance and accounting learning,2018,(25):135.

[2] Zhou pei, li ling, wang ting. How far can financial robots go [J]. Western economic management BBS, 2008,9(6):4-5.

[3] Yu ran, jin Ming. The arrival of financial robot era and the future of traditional accounting [J]. Science and technology economic market,2017,(6):91-92.

[4] Huang jie. "danger" and "opportunity" of accounting personnel under artificial intelligence [J]. Modern economic information,2016 (21):233.

[5] Dai baihua. Adapt to the new normal, promote the integration of development, and actively promote the reform and development of accounting under the "Internet plus" [J]. Chinese CPA,2015 (8) :5-6. 